\title{
Epidermolysis Bullosa a Case Report with Review of Literature
}

\author{
Authors \\ Ravinder Singh $^{1^{*}}$, Abhisekh Thakur ${ }^{2}$, Shikha Verma ${ }^{3}$, Dilbag Singh ${ }^{4}$ \\ ${ }^{1}$ Medical Officer, Dermatology DR RKGMC Hamirpur H.P India \\ ${ }^{2}$ Senior Resident, Department of Dermatology Dr RKGMC Hamirpur H.P India \\ ${ }^{3}$ Senior Resident, Department of Pediatrics Dr RPGMC Kangra H.P India \\ ${ }^{4}$ Senior Resident, Department of Dermatology Dr JLNGMC Chamba H.P India \\ *Corresponding Author \\ Ravinder Singh
}

\begin{abstract}
Epidermolysis bullosa $(E B)$ is defined as group of phenotipically diverse genodermatoses characterized by blisters and erosions of the skin and mucous membranes. The conditions are genetically and clinically heterogeneous and have a very variable severity spectrum. We present a case of 4 years male child with history of blisters and erosions over hands, feet, knees, elbows, face, lips and oral cavity since birth developing after minimal trauma. These lesions heal without atrophic scars. When the child present to us there was no blisters but healed lesions over both upper and lower limbs with scattered crusted erosions were present. Histology was not done as there was no fresh blister at the time of presentation.
\end{abstract}

\section{Introduction}

Epidermolysis bullosa comprises a group of genetically determine skin fragility disorder characterized by blistering of the skin and mucosa following mild trauma. These disorders represent heterogeneous phenotypes and are associated with a variable range of complications, from localized skin fragility to neonatal death ${ }^{[1]}$. This complex and heterogeneous group is classified on the basis of the mode of inheritance, clinical, laboratory and epidemiological studies into three major forms: EB simplex (EBS), junctional EB (JEB), and dystrophic EB (DEB). The most recent classification of EB has been proposed by the third international consensus meeting held in Vienna in $2007^{[2]}$. This classifications added a fourth group to the major EB types, the mixed or Kindler Syndrome. The patients are then separated by major and minor EB subtypes.

\section{Case Report}

A term 4 years old male child born to nonconsanguineous marriage present to Dermatology OPD with history of blisters and erosions following minor trauma since birth. On examination there were no blisters but healed superficial erosions without scarring involving both upper and lower limbs. In upper limbs involvement of dorsum of hands along with both elbows and in lower limbs involvement of dorsum of feet and both knees was present. There were few crusted erosions over face, knee and feet. Nail involvement in the form of absence of all nails of hands and feet was present. Oral involvement in form of erosions, premature loosening and dental pitting was also present. Systemic examination of child was normal. Routine blood investigations were also normal. 
Figure 1: Healed lesion with crusted erosion

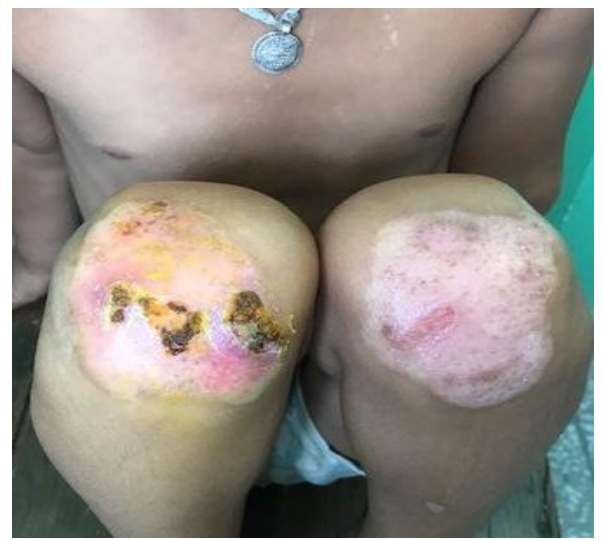

Figure 2: Healed lesion over knees and elbows

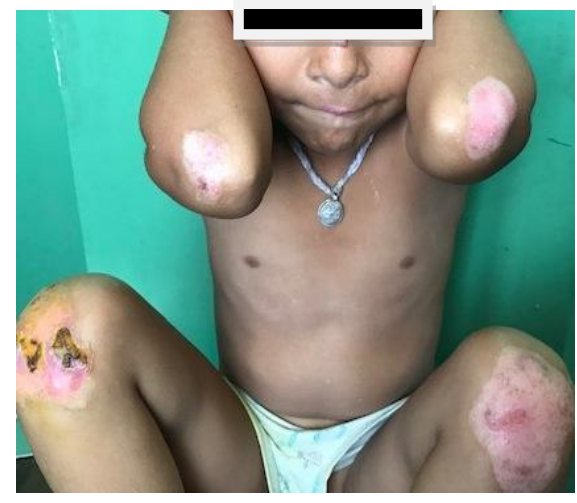

Figure 3: Nail dystrophy with crusted erosion

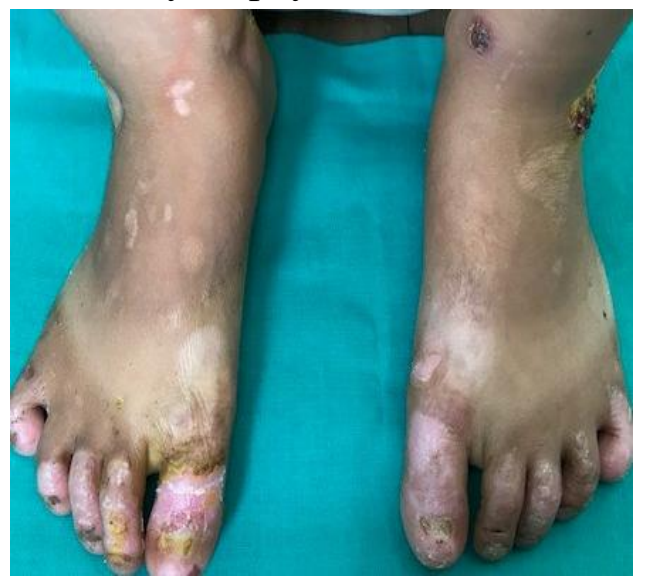

Figure 4: Premature loosing and pitting of teeth

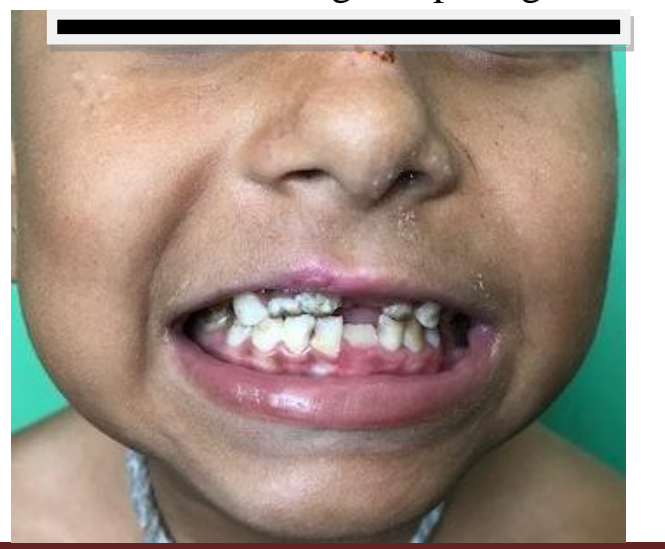

\section{Discussion}

Epidemiology

According to the National EB registry project from USA, the incidence and prevalence of EB are estimated to be 19.60 per million live births and 8.22 per million population, respectively. The incidence and prevalence rates of EB simplex are 10.75 and 4.65, of junctional EB are 2.04 and 0.44 and dystrophic EB dominant type 2.86 and 0.99 and recessive dystrophic EB 2.04 and 0.92, respectively ${ }^{[1]}$. Whereas, according to the epidemiological data from Scotland, the incidence of EBS in 2001 was 33.2 per million and the incidence between 1960 and 1999 were 34.4 per million live births ${ }^{[3]}$. It is supposed the EB simplex is underreported since most of the cases are mild, some studies suggesting that this form is reported in only $10 \%$ of the cases ${ }^{[4]}$. According to the National EB Registry in USA, 92\% of the patients are suffering of EB simplex, 5\% are presenting dystrophic EB, $1 \%$ have junctional EB while $2 \%$ of the cases are unclassified ${ }^{[1]}$.

\section{Pathogenesis}

Any genetic defect affecting the complex adhesion molecules and structures anchoring the dermis against epidermis may cause a type of EB. With the help of immnunohistochemistry, the major epidermolysis bullosa genes identified are those that encode keratins 5 and 14 in $\mathrm{EBS}^{[5]}$. In JEB the underlying defect lies in the hemidesmosomes which tend to be sparse and very small, especially in the more severe forms of the disease and the majority of mutations have been found in the LAMB3 gene ${ }^{[6,7]}$. Immunofluorescence studies have also shown reduced staining of another hemidesmosome-anchoring filament component, BPAG2, or collagen 17 in the skin of patients with generalized atrophic benign EB (GABEB), suggested that mutations in the BPAG2 gene might underlie this condition ${ }^{[8]}$. DEB is caused by mutations in a single gene, COL7A1, encoding the anchoring fibril protein, the type 7 collagen. Quantitative electron microscopy and immuneelectron microscopy have shown complete absence of anchoring fibrils in severe forms of dystrophic 
$\mathrm{E}^{[9]}$. In the milder or more localized form of recessive dystrophic $\mathrm{EB}$, immunoreactivity is present but often attenuated. In fact, Kindler syndrome has now been included as the fourth major EB type, according to the leading authorities [6].

\section{Clinical Features}

The onset of EB is usually at birth or immediately after birth, except EB simplex, a type of EB that can remain undiagnosed until adulthood or not diagnosed at all ${ }^{[9]}$. The hallmark of EB is the skin fragility to minor mechanical trauma, followed by blisters and erosions formation and, in various degrees, occurrence of milia, nail dystrophy or absence, and scar formation ${ }^{[10]}$. Additional findings in EB can be: exuberant granulation tissue localized or generalized keratoderma, dyspigmentation areas, scarce or absent hair and hypo/hyperhydrosis. The fragility of the skin is more accentuated in warm weather or environment (except EB Dowling Meara $)^{[10]}$. Epidemolysis bullosa represents a clinical challenge due to the nature of the skin involvement manifested by continuous blistering, erosions, chronic ulcerations and scarring ${ }^{[11]}$. Therefore a complete clinical exam must include the size, localization and type of the vesicles since all these aspects can guide the clinician toward identification of the type of EB: superficial lesions are manifested as crusted erosions, intraepidermal vesicles are flaccid and can increase in size under pressure, blisters situated in the lamina lucida are tensed and recover with atrophy but with scars while blisters in the lamina densa are recovering with scars and milia formation ${ }^{[4]}$. In our case patient usually have flaccid blisters and erosions along with minimal mucosal involvement and nail dystrophy, is a form of EB simplex

Table 1: Inheritance and clinical features of different types of Epidermolysis bullosa

\begin{tabular}{|l|l|l|}
\hline Type & Inheritance & Clinical feature \\
\hline EB simplex & Autosomal & Localized blisters or \\
dominant, & grouped vesicles, \\
& rarely & limited mucosal \\
recessive & $\begin{array}{l}\text { involvement, } \\
\text { palmoplantar } \\
\text { hyperkeratosis, nail } \\
\text { dystrophy, normal } \\
\end{array}$ & teeth and hair \\
\hline
\end{tabular}

\begin{tabular}{|l|l|l|}
\hline Junctional EB & $\begin{array}{l}\text { Autosomal } \\
\text { recessive }\end{array}$ & $\begin{array}{l}\text { Widespread } \\
\text { blistering, scarring, } \\
\text { significant } \\
\text { granulation tissue, } \\
\text { severe mucosal } \\
\text { involvement, dental } \\
\text { pitting, alopecia, nail } \\
\text { dystrophy }\end{array}$ \\
\hline Dystrophic EB & $\begin{array}{l}\text { Both } \\
\text { Autosomal } \\
\text { dominant and } \\
\text { recessive }\end{array}$ & $\begin{array}{l}\text { Hemorrhagic blisters, } \\
\text { scarring, milia, } \\
\text { pseudosyndactyly, } \\
\text { severe mucosal } \\
\text { involvement, } \\
\text { physical and sexual } \\
\text { retardation, } \\
\text { significant morbidity } \\
\text { and mortality }\end{array}$ \\
\hline
\end{tabular}

\section{Diagnosis}

The clinical examination and the familial history may help to exclude other causes of blisters and erosions but the gold standard for determining the level of the blisters in EB diagnosis is cutaneous biopsy and examination of the extracted material under transmission electron microscope (TEM) ${ }^{[4,12]}$. However, it is time consuming, expensive, and operator dependent. Immunofluorescence mapping is as diagnostically reliable as TEM and is based on the detection of structural proteins of keratinocytes or of the dermo-epidermal junction using poly or monoclonal antibodies. It is used preferentially because of rapidity of results, ease in performance, and the ability to use the same specimens for study with monoclonal antibodies. Mutational analysis is the ultimate means of determining the mode of inheritance and the precise site and type of molecular mutation. Prenatal and preimplantation diagnosis can also be performed, so that genetic counselling can be done. Mutational and linkage analysis are done using DNA from the proband and his or her relatives ${ }^{[13]}$. For the DNA-based diagnosis, the specialists must select the targeted genes after all these tests. It is also important to mention that the molecular diagnosis of $\mathrm{EB}$ is difficult because some of the involved genes are relatively long and the number of spot mutations is low ${ }^{[12]}$. The complete diagnosis of an individual with EB must be completed by evaluation of the possible complications: anemia (blood count and 
iron), infection (cultures), digestive tract problems (for esophageal strictures, pyloric atresia.

\section{Management}

Avoidance of provoking factors for blistering remains the mainstay of management. Heat and humidity lower the threshold for blistering in patients with EB simplex, and therefore measures to reduce both these factors are important. Nursing the babies on thick foam pads protects them from undue trauma induced blistering. The erosions should be cleaned with sterile normal saline and covered with nonadherent dressings. Topical antibiotics are generally avoided because of the risk of emergence of antibiotic resistant bacteria. Good oral hygiene, treatment of caries and reconstructive procedures in the form of crown placements and tooth implants should be applied to maintain function. Esophageal strictures require balloon dilatation while constipation needs to be managed with adequate fiber diet and stimulant laxatives. Early exercises and physiotherapy may help reduce the severity of contractures, which are almost inevitable and surgical release of the contracted fingers then needs to be done involving skin grafting and postoperative splinting. As far as systemic treatment is concerned, none of the agents studied so far have proved to be effective in controlling blistering in patients with EB. While systemic corticosteroids are generally avoided because of the high risk of complications, a randomized controlled trial with phenytoin no more supports its use in patients with RDEB as no significant effect was noted over placebo in this study ${ }^{[14]}$. The trials with tetracyclines have failed to provide any conclusive evidence owing to the high drop-out rates ${ }^{[15]}$. Other systemic agents tried in small case series include minocycline, vitamin $\mathrm{E}$, cyclosporine and retinoids; currently, there is no reliable clinical trial evidence for interventions in $\mathrm{EB}^{[16]}$. Gene therapy is the ultimate goal which is likely to become a reality in the near future. The objective is to introduce one normal allele into somatic cells that would replace one of the two mutant alleles in recessive forms of EB. For autosomal dominant forms, the objective is to inactivate or nullify the action of the mutant allele rather than introduction of the normal allele ${ }^{[17]}$.

\section{References}

1. Fine JD, Johnson LB, Suchindran C, Moshell A, Gedde-Dahl T, Jr. The epidemiology of inherited epidermolysis bulllosa: Findings in the US, Canadian and European study populations. In: Fine JD, Bauer EA, Mc Guire J, Moshell A, editors. Clinical, epidemiological and laboratory advances, and the findings of the national epidermolysis bullosa registry. Baltimore: John's Hopkings university press; 1999. p. 101-13.

2. Fine JD, Eady RA, Bauer EA, Bauer JW, Bruckner-Tuderman L, Heagerty A, et al. The classification of inherited epidermolysis bullosa (EB): Report of the Third International Consensus Meeting on Diagnosis and Classification of EB. J Am Acad Dermatol 2008;58:931-50.

3. Horn HM, Priestley GC, Eady RA, Tidman MJ. The prevalence of epidermolysis bullosa in Scotland. Br J Dermatol 1997;136: 560-4.

4. Marinkovich PM, Ortonne JP, Wells MJ, Perry V, Gelfand JM, James WD et al. Epidermolysis

Bullosa. http://emedicine.medscape.com/article/1062 939-overview.

5. Mc Grath JA, Mc Millan JR, Dunnil M, Pulkkinen L, Christiano AM, Rodeck CH, et al. Genetic basis of lethal junctional epidermolysis bullosa in an affected fetus: Implications for prenatal diagnosis in one family. Prenat Diagn 1995;15:647-54.

6. Eady RAJ, McGrath JA, McMillan Jr. Ultrastructural genetic disorder of skin: The dermal-epidermal junction. J Invest Dermatol 1994;103:13S-18S.

7. Christiano AM, Uitto J. Molecular complexity of the cutaneous basement membrane zone. Exp Dermatol 1996;5:1-11.

8. Jokman MF, de Jong MC, Heeres K, Pas HH, Vander Meer JB, Owaribe K, et al. 180- 
$\mathrm{kD}$ bullous pemphigoid antigen (BP180) is deficient in generalized atrophic benign epidermolysis bullosa. J Clin Invest 1995;95:1345-52.

9. McGrath JA, Ishida-Yamamotoa, O'Grady A, Leigh IM, Eady RA. Structural variation in anchoring fibrils in dystrophic epidermolysis bullosa: Correlation with type VII collagen expression. J Invest Dermatol 1993;100:366-7.

10. Fine J-D. Inherited epidermolysis bullosa. Orphanet Journal of Rare Diseases 2010, 5: 12.

11. Uitto J, Eady R, Fine JD, Feder M, Dart J. The DEBRA International Visioning/ Consensus Meeting on Epidermolysis Bullosa: summary and recommendations. J Invest Dermatol 2000; 114(4): 734-737.

12. Sawamura D, Nakano H, Matsuzaki Y. Overview of epidermolysis bullosa. J Dermatol 2010; 37(3): 214-219.

13. Castiglia D, Zambruno G. Molecular testing in epidermolysis bullosa. Dermatol Clin 2010;28:223-9.

14. Caldwell-Brown D, Stern RS, Lin AN, Carter DM. Lack of efficacy of phenytoin in recessive dystrophic epidermolysis bullosa. N Engl J Med 1992;327:163-7.

15. Hansen SK, Veien NK. Oxytetracycline in epidermolysis bullosa simplex. A doubleblind placebo-controlled trial. J Eur Acad Dermatol Venereol 1996;6:277-8.

16. Langan SM, Williams HC. A systematic review of randomized controlled trials of treatments for inherited forms of epidermolysis bullosa. Clin Exp Dermatol 2008;34:20-5.

17. Featherstone C. Epidermolysis Bullosa: From Fundamental Molecular Biology to Clinical Therapies. J Invest Dermatol 2007;127:256-9. 